\title{
SEASONAL AND INTRA-SEASONAL VARIABILITY OF SEA SURFACE TEMPERATURE IN PARI ISLAND-JAKARTA, INDONESIA
}

\author{
Corry Corvianawatie \\ Research Center for Oceanography, Indonesian Institute of Sciences (LIPI) \\ Jalan Pasir Putih I Ancol Timur, Jakarta Utara, 14430, Indonesia \\ Corresponding author e-mail: corr002@lipi.go.id
}

Submitted: 26 Maret 2019 / Revised: 27 Juni 2019 / Accepted: 27 Juni 2019

http://doi.org/10.21107/jk.v12i1.5092

\begin{abstract}
Sea Surface Temperatures (SSTs) is one of the most important oceanographic parameter that could affect the marine life, especially coastal ecosystem. SSTs data varies in hourly, daily, seasonal, annual, inter-annual, and even in longer time scales. This condition makes any studies using instantaneous measurement could turn into misleading report due to the lack of time series SSTS data. Thus, the aim of this study is to understand the seasonal and intra-seasonal SSTs dynamics in Pari Island using continuous measurement from temperature logger. This study found that the double peaks of SSTs in May and November are correspond to the period of transitional monsoon. Conversely, the two minimum SSTs in February and August were correspond to the peak of northwest monsoon and southeast monsoon respectively. In addition to seasonal pattern, the slightly dominant intra-seasonal variability of SSTs was found in the period of 57 and 86 days. Those predominant signals suggested represent the Madden-Julian Oscillation phenomena.
\end{abstract}

Keywords: SST, seasona, intra-seasonal, Java Sea, monsoon, MJO

\section{INTRODUCTION}

Elevated sea surface temperatures (SSTs) suggested have a significant role as the main cause of coral bleaching (Brown and Suharsono, 1990; GBRMPA, 2017; Wouthuyzen et al., 2015; Wouthuyzen et al., 2018). Massive coral bleaching in the coastal area of Indo-Pacific Ocean was found in the earlier of 2016 as the impact of giant El Niño. Several coral reef area were reported have been damaged by giant El Niño 2016 including Great Barrier Reef Marine Protected Area (GBRMPA, 2017) and coastal area of Indonesian Seas (Wouthuyzen et al., 2018). Nearly $29 \%$ of shallow-water coral in Great Barrier Reef was lost after the persistence increase of SSTs above its climatological threshold (GBRMPA, 2017). Similar to Indonesian Seas, several areas stretching from the eastern to the western part were experienced coral bleaching due to SSTs warming (Wouthuyzen et al., 2018).
Pari Island - Thousand Islands Jakarta is one of the coastal areas suspected to have an indirect impact of increased SSTs during the giant El Niño 2016. However, this kind of environmental damage could have been mitigated if we understand the variability of SSTs well. Unfortunately, long time series insitu SSTs data were not available to resolve its climatological pattern. Moreover, the variability of SSTs in small scale area such as Pari Island waters is rather complex than variability of SSTs in the open oceans. It is suggested that SSTs in Pari Island mainly driven by monsoonal winds in the annual scale (Halkides et al., 2011; Kida and Richards, 2009; Qu et al., 2005). Local processes such as tidal mixing and air-sea heat fluxes suggested could affect SST variability (Gordon, 2005) . Further, SST also varies due to larger scale climate phenomena such as Madden-Julian Oscillation (MJO) (Madden and Julian, 1994; Napitu et al., 2015; Zhang, 2008), Indian Ocean Dipole (IOD) (Saji et al., 1999), and El Niño Southern Oscillation (ENSO) (McBride et 
al., 2003). In some cases, positive or negative phase of IOD and ENSO lead to extreme SSTs anomalies.

The extreme SSTs anomalies which is stand still for a few weeks or months could harm coral reef ecosystem. It could be the main factor of coral bleaching events and ultimately may lead to coral death. However, we could develop the system to forecast the potential of coral bleaching event by using the SSTs as one of the considered parameters. National Oceanographic and Atmospheric Administration (NOAA) have been developed this system by using ocean and atmospheric data from local stations and satellites. The same procedure should be applied in coastal area such as Pari Island. Thus, for the preliminary research, the aim of this study is to understand the dynamics of SSTs by using continuous deployment of temperature logger.
The information of seasonal and intraseasonal SSTs data could be used as the basis for determining the SSTs anomalies in Pari Island.

\section{MATERIALS AND METHODS}

SSTs data were collected using temperature logger which is mounted at Marine Protected Area of Pari Island (Figure 1). Precisely, it is located at the south-east part of Pari Island with the coordinate of $106.612{ }^{\circ} \mathrm{E}$ and 5.8706 ${ }^{\circ} \mathrm{S}$. Coral reef ecosystem lied beneath this area. Moreover, the south-east part of Pari Island is suggested get the direct impact of anthropogenic stress from Jakarta mainland. In order to resolve the SST variability of this area, logger instrument was attached at 4meter depth and logged for 17 months in onehour interval starting from November 2016 until March 2018.

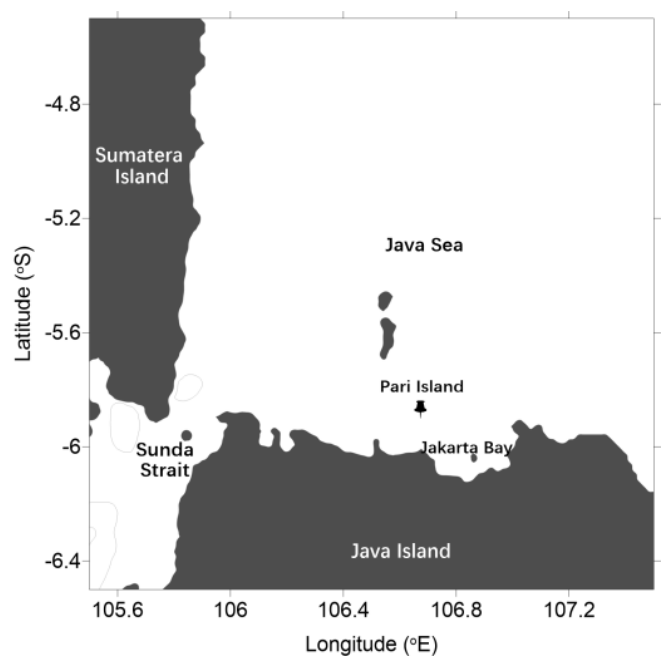

Figure 1. The location of $\mathrm{HOBO}$ temperature logger at the south-east part of Pari Island.

Raw SSTs data collected by temperature logger were containing noises due to high frequency signals affected by tides. Thus, we applied simple median filter function for 24 hours' periods to remove those noises. Then, Fast Fourier Transform (FFT) were applied to the filtered data to overview any signals which composed observed SSTs data. SSTs data suggested have a seasonal pattern due to the effect of monsoonal wind over Indonesian Seas. It is also suggested that the climatic phenomena such as ENSO, IOD, and MJO have important role on SSTs variability at this area. To confirm this hypothesis, several climatic indexes such as Oceanic Niño Index (ONI), Dipole Mode Index, and MJO Index were also used in this study.

\section{RESULTS AND DISCUSSION}

Temperature logger instrument recorded SSTs data for 17 months starting from November $1^{\text {st }}$, 2016 until March $31^{\text {st }}, 2018$ in an hour interval. Thus, besides records the monthly variability, data logger also records daily variabilities as the impact of short-term ocean and atmosphere dynamics. Based on our assessment, the period of SST measurement 
can be classified as normal condition. This statement is supported by the IOD index, Oceanic Niño Index (ONI), and MJO Index data which are showing the relatively normal state of the ocean. As we know, the climate phenomenon such as IOD, ENSO, and MJO induce the SSTs anomalies at several areas of Indonesian Seas, including Pari Island waters.

\section{Normal states of IOD, ENSO, and MJO}

Indian Ocean Dipole (IOD) is the inter-annual climate variability in the Indian Ocean that were characterized by a pattern sea surface temperature anomaly at Sumatra (Indonesia) and western Indian Ocean, with accompanying wind and precipitation anomalies. Beside its impact on SSTs variabilities, IOD also cause severe rainfall and drought at Africa or Indonesia, dependent on the dipole mode phase (Saji et al., 1999). The phase of IOD characterized by the Dipole Mode Indexes (DMI) which represent the SSTs gradient between eastern and western part of the Indian Ocean. DMI positive were characterized by greater than $+0.5^{\circ} \mathrm{C}$ SST gradient, while DMI negative were characterized by lower than $-0.5^{\circ} \mathrm{C}$ SSTs gradient. Based on the historical data, DMl indexes were in the range of -0.5 to $+0.5{ }^{\circ} \mathrm{C}$ for November 2016 to March 2018 periods. It means that there is no significant anomalies of SSTs in Indian Ocean (Figure 2).

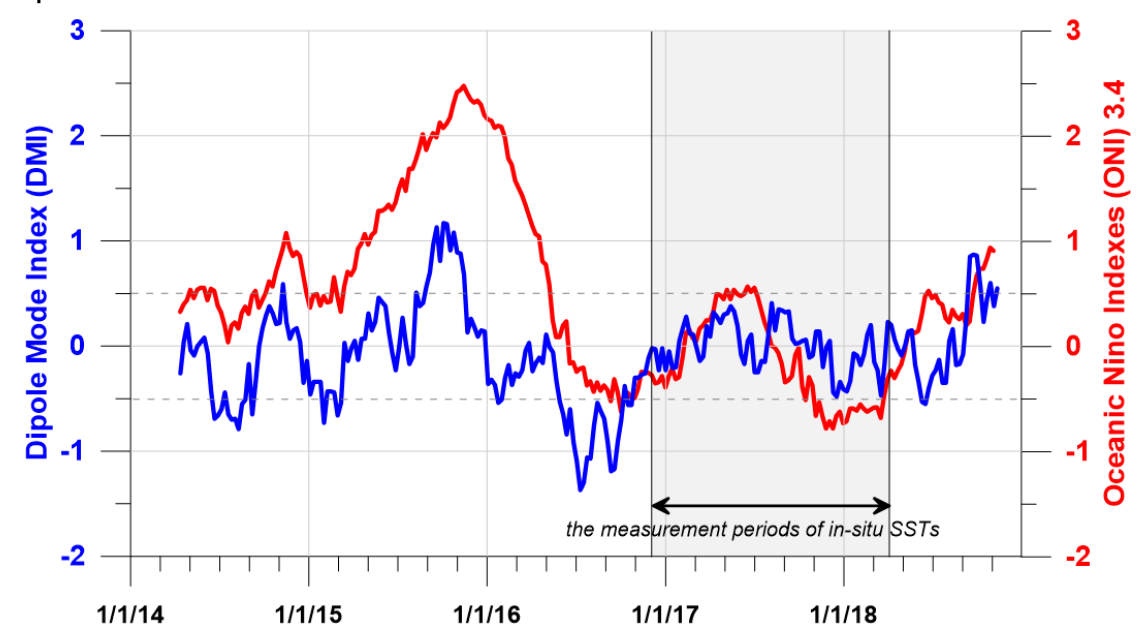

Figure 2. Dipole Mode Indexes (DMI) and Oceanic Nino Indexes (ONI) 3.4 during 2014 - 2018. Highlighted data represent the periods of in-situ SSTs measurement in Pari Island-Jakarta, Indonesia.

Another important coupled ocean-atmospheric phenomenon is El Niño Southern Oscillation (ENSO). ENSO caused by anomaly of the trade winds over Pacific Oceans (Clarke, 2014). ENSO have two phase called El Niño and La Niña, which identified by the SSTs anomaly at the Central Pacific Ocean (Nino 3.4 region). Biggest El Niño event was occurred in April 2015 - March 2016 with the maximum SSTs anomaly reached $+2.5{ }^{\circ} \mathrm{C}$. However, the phase of ENSO turns into normal condition in May 2016 - March 2018. Even there is SSTs cooling on November 2017 until March 2018, the magnitude is very small. They were in the range of -0.6 to -0.7 degree Celcius (Figure 2). Also, in April 2018 we could see the phase of ENSO were already back to its normal condition. Based on this data, we could assume that the ENSO variability did not have significant impact on in-situ data at the periods of in-situ measurements.

Shorter than ENSO and IOD, there is an atmospheric circulation which slowly propagate $(\sim 5 \mathrm{~m} / \mathrm{s})$ in eastward direction across the equatorial Indian Ocean and Pacific Ocean called Madden-Julian Oscillation (MJO). MJO characterized by eastward moving center of strong deep convection and precipitation in their active phase, while weak deep convection and precipitation in their inactive phase. MJO have temporal period around 30 to 100 days (Zhang, 2008). Previous study about MJO stated that the 
power peak of MJO is highly varies within this range (Zhang, 2008). It is suggested that the interval between two consecutive events is irregular and their propagation speeds may
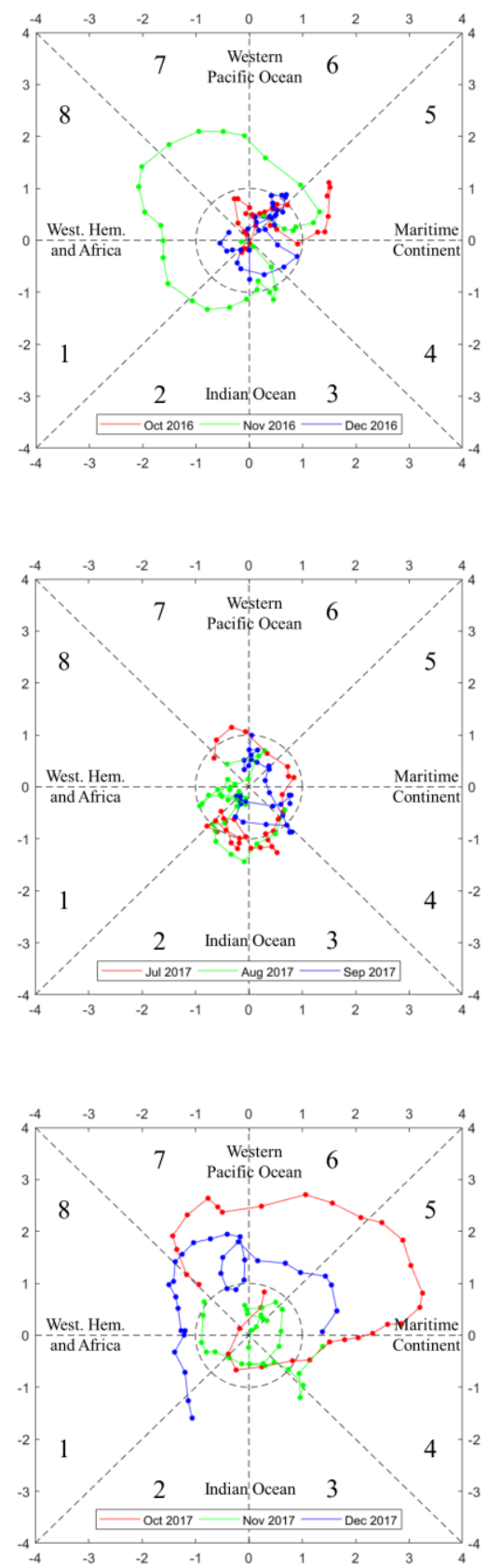

vary (Zhang, 2008). Thus, the oscillation periods of MJO is remain unclear and being the object that difficult to predict.
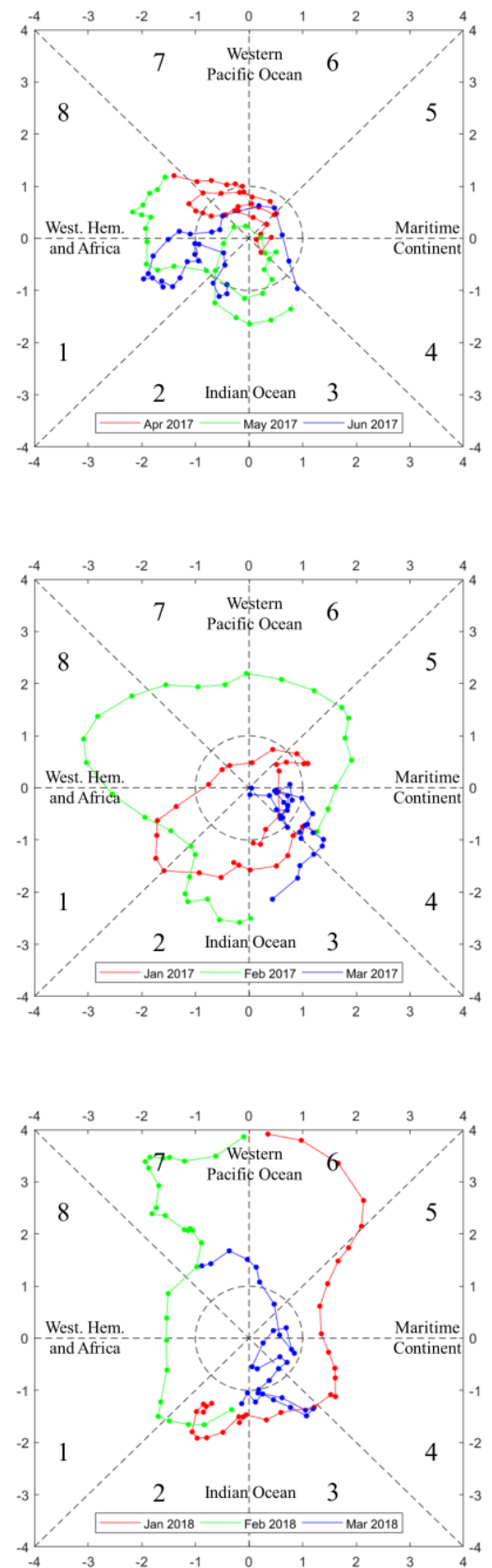

Figure 3. MJO indexes in the period of October 2016 until March 2018. There is no significant MJO activity in the region 4 which is represent the area of Western Indonesian Seas.

The progression of MJO in different phases could be seen from MJO phase diagram as follows (Figure 3). This diagram represents the Real-Time Multi Variate MJO Index series 1 (RMM1) and series 2 (RMM2) data which calculated from the cloud amount and winds at upper and lower levels of the atmosphere to provide a measure of the strength and location of the MJO (Wheeler and Hendon, 2004). Region 4 were representing the area of western Indonesian Seas including Java Seas and Pari Island. Based on the historical data, 
there is no significant MJO event in western Indonesian Seas during the observation periods (Figure 3). In summary, we could assume that SSTs data in this study were not interrupted either by ENSO, IOD, or MJO.

\section{Variability of Sea Surface Temperatures}

Qualitatively, based on the recorded data, there are two maximum SST in one-year period. The maximum SSTs were identified in November and May, while the minimum SSTs were found in February and August (Figure 4). In more detailed analysis, Fast Fourier Transform (FFT) was applied to the time series SSTs data. FFT analysis were transformed the time domain SSTs into the frequency domain. By using FFT analysis, we could identify several dominant SSTs signals which are indicated by their SST amplitude (Figure 5).

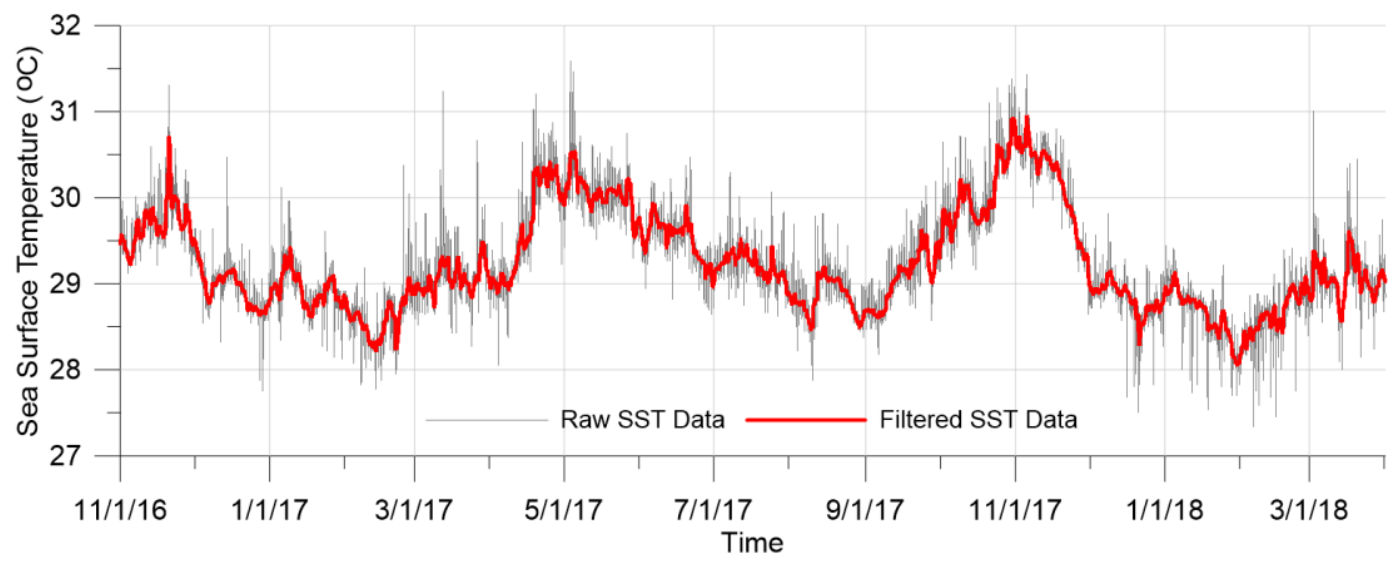

Figure 4. SSTs data of Pari Island observed using HOBO temperature logger from November 2016 to March 2018.

FFT analysis figure out that mean value of SSTs in Pari Island is found to be $29.234{ }^{\circ} \mathrm{C}$. The highest amplitude of decomposed SSTs signal is about $0.644{ }^{\circ} \mathrm{C}$. This signal represents seasonal variability with the period of 172 days or nearly 6 months. It means Pari Island have twice maximum and minimum SSTs every year. Maximum SSTs in November and May are coincide with transitional monsoon. Conversely, SSTs reaches their minimum level during the peak of northwest and southeast monsoon on February and August. This condition might be correlated to the surface wind speed over this area.

Monsoonal winds have a huge impact on SST variability over Java Seas and Jakarta Bay. One of the reason is due to the shallow bottom profile of this area. Monsoonal wind could be the mixing agent for seawater either horizontally or vertically. As the result, during the peak of northwest and southwest monsoon, the wind mixing the seawater intensively. The vertical mixing of seawater could combine the warm water at the surface layer and cool water at subsurface layer into relatively cooler water at the surface. Thus, based on the observation data we can find the minimum SSTs were occurred during the peak of northwest and southeast monsoon. Conversely, during the transitional periods, the wind speed is weaker and so do the mixing. As the impact, SSTs become warmer during the transitional periods.

Variability of sea surface temperature due to the monsoonal signal should be in the range of 28.60 to $29.870{ }^{\circ} \mathrm{C}$. However, based on the recorded data, we could find the lowest SSTs data at $27.333{ }^{\circ} \mathrm{C}$ and the highest at 31.586 ${ }^{\circ} \mathrm{C}$. This condition is possible because in addition to dominantly seasonal signal, there are also daily variability due the tides and some pre-dominant signals at the period of 52 days ( 2 months) and 86 days ( $\sim 3$ months). The amplitude of pre-dominant signals was $0.139^{\circ} \mathrm{C}$ and $0.179^{\circ} \mathrm{C}$ respectively. This kind of signal can be classified as intra-seasonal signals. 


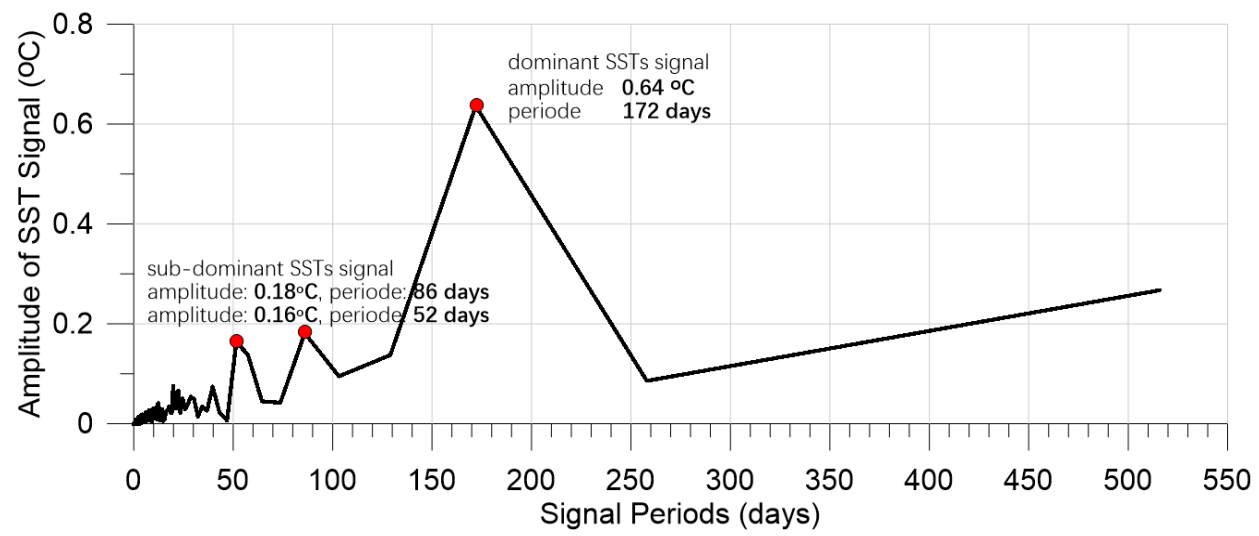

Figur 5. Periodogram of sea surface temperature data in Pari Island during November 2016 until March 2018.

One of regional climatic phenomena with intraseasonal time scale is Madden-Julian Oscillation (MJO). This oscillation is associated to the movement of convection cloud from the western to eastern tropical region. It is suggested that MJO might be affected the SST variability in the Pari Island waters. The sub-dominant signals in the periods of 52 and 86 days might be correlated to these phenomena. As the MJO characterized by eastward moving center of convection and precipitation, they could affect the SSTs variability over their pathways. During the active phase of MJO, there will be strong convection and precipitation which is produced by warmer SSTs. Conversely, there will be weak convection and precipitation during the inactive phase of MJO, which is produced by cooler SSTs.

\section{CONCLUSIONS and SUGGESTION}

Sea surface temperature in Pari Island have a seasonal variability which enforced by the monsoonal winds in 172 days' period. The effect of monsoonal system is quietly significant and induce the seasonal oscillation for $\pm 0.644^{\circ} \mathrm{C}$ from their annual average of $29.245^{\circ} \mathrm{C}$ during the observational periods. Smaller magnitude of SSTs oscillation has been found in the intra-seasonal periods of 52 and 86 days, which might be correlated to MJO events over tropical oceans. This study has been used comprehensive observation of SSTs data in Pari Island, Jakarta Bay and suggested have important information for coastal management in this area. The observation data represent the normal climatic condition without the significant disturbance of MJO, ENSO, and IOD on SSTs variability. Thus, the seasonal SSTs data $29.234^{\circ} \mathrm{C}$ $\left( \pm 0.644^{\circ} \mathrm{C}\right)$ which is observed in November
2016 - March 2018 could be used as the recent baseline to determine the extreme SSTs anomaly at this area.

\section{ACKNOWLEDGEMENTS}

This research is supported by DIPA Loka Pengembangan Kompetensi SDM Oseanografi LIPI 2016 - 2018. Also we would like to thanks to Ahmad Rezza Dzumalex and Salim for their help during the deploy and retrieve process of logger instrument in Pari Island.

\section{REFERENCES}

Brown, B. E. \& Suharsono (1990). Damage and recovery of coral reefs affected by El Niño related seawater warming in the Thousand Islands, Indonesia. Coral reefs, 8(4), 163-170.

Clarke, A. J. (2014). El Niño physics and El Niño predictability. Annual review of marine science, 6, 79-99. Doi: 10.1146/annurev-marine-010213135026

GBRMPA - Great Barrier Reef Marine Park Authority (2017). Final report: 2016 coral bleaching event on the Great Barrier Reef, GBRMPA, Townsville, 37 pp.

Gordon, A. (2005). Oceanography of the Indonesian Seas and Their Throughflow. Oceanography, 18(4), 14-27. Doi: 10.5670/oceanog.2005.01

Halkides, D., Lee, T., \& Kida, S. (2011). Mechanisms controlling the seasonal mixed-layer temperature and salinity of the Indonesian seas. Ocean Dynamics, 61(4), 481-495. Doi: 10.1007/s10236-010-0374-3. 
Kida, S. \& Richards KJ. (2009). Seasonal sea surface temperature variability in the Indonesian Seas. Journal of Geophysical Research: Oceans, 114(6):1-17. Doi: 10.1029/2008JC005150, 2009

Madden, R. A., \& Julian, P. R. (1994). Observations of the 40-50-day tropical oscillation-A review. Monthly Weather Review, 122(5), 814-837.

McBride, J. L., Haylock, M. R., \& Nicholls, N. (2003). Relationships between the Maritime Continent heat source and the El Niño-Southern Oscillation phenomenon. Journal of Climate, 16(17), 2905-2914.

Napitu, A. M., Gordon, A. L., \& Pujiana, K. (2015). Intraseasonal sea surface temperature variability across the Indonesian Seas. Journal of Climate, 28(22), 8710-8727. Doi: 10.1175/JCLID-14-00758.1

Qu, T., Du, Y., Strachan, J., Meyers, G., \& Slingo, J. (2005). Sea Surface Temperature and Its Variability in the Indonesian Region. Oceanography, 18(4), 50-61.

Saji, N, Goswami B, Vinayachandran P, Yamagata T. (1999). A dipole mode in the Tropical Ocean. Nature, 401(6751):360-3.

Wheeler, M. C., \& Hendon, H. H. (2004). An all-season real-time multivariate MJO index: Development of an index for monitoring and prediction. Monthly Weather Review, 132(8), 1917-1932. Doi: $\quad 10.1175 / 1520-$ 0493(2004)132<1917:AARMMl>2.0.C $0 ; 2$

Wouthuyzen, S., Abrar, M., \& Lowrens, J. (2015). Bleaching Incident of 2010 in Indonesian Waters Revealed through Analysis of Sea Surface Temperature, Oseanologi dan Limnologi di Indonesia, 1(3), 305-327.

Wouthuyzen, S., Abrar, M., \& Lowrens, J. (2018). A Comparison between 2010 and 2016 El Niño induced coral bleaching in the Indonesian waters, IOP Conference Series: Earth and Environmental Science, 118(1), 021051. Doi: :10.1088/17551315/118/1/012051

Zhang, C. (2008). Madden Julian Oscillation, Review of Geophysics, 43(2005), 136. Doi: 10.1029/2004RG000158. 